\title{
Linfangiectasia intestinal associada à linfangite lipogranulomatosa em cão da raça Pit Bull
}

Intestinal Lymphangiectasia associated with lipogranulomatous lymphangitis in a Pit Bull breed dog

\author{
Wanessa Krüger Beheregaray ${ }^{1}$, Giordano Cabral Gianotti ${ }^{1}$, Marianne Lamberts ${ }^{2}$, Saulo Petinatti \\ Pavarini $^{3}$, Rafael Rodrigues Ferreira ${ }^{3}$, Luciana de Almeida Lacerda ${ }^{3}$ \& Emerson Antonio Contesini ${ }^{4}$
}

\begin{abstract}
RESUMO
A linfangiectasia é uma enteropatia desperdiçadora de proteínas, que ocorre devido à drenagem ineficaz da rede linfática, podendo estar acompanhada por uma linfangite lipogranulomatosa, que é a reação ao material de vasos linfáticos que se romperam. Através dos sinais clínicos, que incluem diarréia crônica, efusões cavitárias, edema de membros e emagrecimento progressivo, em conjunto com achados histopatológicos, se obtém o diagnóstico. Este estudo tem como objetivo descrever os aspectos clínicos e patológicos de um caso de linfangiectasia intestinal associada à linfangite lipogranulomatosa em um cão macho, 14 meses de idade, da raça pit bull, que foi atendido no Hospital de Clínicas Veterinárias da Universidade Federal do Rio Grande do Sul. O animal apresentava aumento abdominal, dispnéia, anorexia e cansaço. Em punção abdominal e torácica, observou-se um líquido esbranquiçado classificado, após análise, como quilo. Optou-se, então, pela laparotomia exploratória para identificação de possíveis causas para a alteração, mostrando obstrução do linfonodo mesentérico e pequenos nódulos brancos e irregulares na serosa do intestino delgado. Foi instituído o tratamento com dieta hipocalórica; porém, o paciente acabou indo a óbito decorridas três semanas de tratamento. Aliando-se os sinais clínicos aos exames laboratoriais e achados de necropsia, chegou-se ao diagnóstico definitivo: linfangiectasia intestinal associada à linfangite lipogranulomatosa.
\end{abstract}

Descritores: doença intestinal crônica, enteropatia, linfangiectasia, linfangite lipogranulomatosa, cão.

\section{ABSTRACT}

The lymphangiectasia is a protein-losing enteropathy coming from a fainling of lynphatics vessels flow. Lipogranulomatous lymphangitis could occour together with lymphangiectasia after reactions by substances witch are present in lynphatics vessels. Clinical signs include chronic diarrhea, peritoneal and pleural effusion, edema of the limbs and progressive weight loss. The final diagnoses were based on clinical signs together with histological findings. The aim of this paper is to describe clinical and pathlogical findings in a case of intestinal lymphangiectasia associated with lipogranulomatous lymphangitis in a male, 14-months-old, pit bull bread dog was referred at Hospital de Clínicas Veterinárias on Universidade Federal do Rio Grande do Sul. The dog was presented with distended abdomen, dyspnea, anorexia and lethargy. At abdominal and thoracic punction were revealed a white fluid classified, after analyse, like chylo. At exploratory surgery a mesenteric lymphonode obstruction was seen and multiple small white lesions occurring along lymphatic vessels on the serosal surface of the small intestine. The treatment was done with low calorie diet. Three weeks later, the patient had died. The necropsy, clinical sings and case evolution, lead to intestinal lymphangiectasia with lipogranulomatous lymphangitis diagnosis.

Key words: chronic enteric disease, enteropathy, lymphangiectasia, lipogranulomatous lymphangitis, dog. 


\section{INTRODUÇÃO}

A linfangiectasia (LI) é uma enteropatia desperdiçadora de proteínas, crônica em cães, caracterizada por uma disfunção que leva à dilatação acentuada da rede linfática intestinal, liberando a linfa no interior do lúmen por meio de ruptura ou extravasamento, causando perda de seus constituintes [1,2,6,11]. Possíveis causas para LI incluem malformação congênita, infiltração ou obstrução dos vasos, drenagem anormal ou aumento da produção de linfa $[2,6]$. Clinicamente, os sinais mais comuns são diarréia crônica, flatulência, vômitos esporádicos, emagrecimento progressivo, letargia, edema do tecido subcutâneo, distensão fluida do abdômen (ascite) e desconforto respiratório (hidrotórax) [1,7]. As alterações laboratoriais incluem hipoalbuminemia, hipoglobulinemia, linfopenia, hipocalcemia e hipocolesterolemia [7]. O exame de necropsia, fundamental para o diagnóstico definitivo, revela alterações na mucosa intestinal, que apresenta vilosidades brancas e proeminentes e nódulos brancos na serosa do intestino delgado, principalmente na inserção com o mesentério. Histologicamente, há marcada ectasia dos vasos quilíferos da região [7].

A necropsia também é fundamental para diagnosticar a linfangite lipogranulomatosa (LL) que é uma lesão que pode acompanhar a LI. Caracterizase pela formação de lipogranulomas como reação granulomatosa ao material proveniente dos vasos linfáticos localizados no intestino [7].

Este relato tem como objetivo descrever os aspectos clínicos e patológicos de um caso de linfangiectasia intestinal associada à linfangite lipogranulomatosa em um cão.

\section{RELATO DE CASO}

Um cão macho, de 14 meses de idade, da raça pit bull, foi atendido no Hospital de Clínicas Veterinárias da Universidade Federal do Rio Grande do Sul (UFRGS), com aumento de volume abdominal, dificuldade respiratória, anorexia, diarréia crônica e cansaço. Apresentava mucosas normocromadas, temperatura retal normal, desidratação de $5 \%$, abdômen distendido e abafamento dos sons cardíacos. O exame ecográfico mostrou líquido livre abdominal com pouca celularidade e fígado hiperecogênico. $\mathrm{O}$ exame radiográfico do tórax apresentou características de derrame pleural. As análises laboratoriais revelaram quadro de linfopenia, hipoproteinemia, hipoalbuminemia. Foram drenados por punção aproximadamente
2,5L do abdômen e 1,46L do tórax de líquido com aspecto leitoso.

$\mathrm{Na}$ tentativa de esclarecer as causas da efusão optou-se por fazer uma laparotomia exploratória, na qual colheu-se mais 3,2L do líquido. Os linfonodos mesentéricos e tecidos circunjacentes apresentavam placas esbranquiçadas. Para corar a rede linfática, injetou-se $20 \mathrm{~mL}$ de solução estéril de azul de metileno no linfonodo, observando-se, então, o extravasamento da solução na mesma região. Apenas uma pequena quantidade de solução progrediu em $2,0 \mathrm{~cm}$ através dos vasos linfáticos, caracterizando uma obstrução (Figura 1). Foi realizada uma incisão na porção muscular do diafragma, de aproximadamente $1,5 \mathrm{~cm}$, para que o líquido presente no tórax drenasse para o abdômen. Da cavidade abdominal a drenagem ocorreria através de uma sonda de foley.

Iniciou-se o tratamento clínico com a drenagem abdominal e dieta hipocalórica - visando diminuir a quantidade da efusão. Após duas semanas, a quantidade de efusão abdominal diminuiu cerca de $80 \%$, com o líquido passando a ter características de um transudado. Mesmo assim, a albumina plasmática passou de $25,1 \mathrm{~g} / \mathrm{dL}$ para $13,3 \mathrm{~g} / \mathrm{dL}$. Na quarta semana, houve uma piora do quadro, com necessidade de drenagem abdominal, diarréias mais freqüentes, anorexia e dificuldade respiratória, levando o animal a uma parada cardio-respiratória irreversível.

$\mathrm{O}$ animal foi encaminhado para o exame de necropsia. $\mathrm{O}$ exame macroscópico revelou a presença de cerca de $2 \mathrm{~L}$ de um líquido leitoso (ascite quiloso), associado a grande quantidade de fibrina em toda cavidade abdominal (Figura 2). As alças intestinais apresentavam-se aderidas entre elas, espessadas, com uma mucosa macia e de aspecto aveludado. Na serosa havia pequenas nodulações ( $3 \mathrm{~mm}$ de diâmetro) lisas, elevadas, firmes e esbranquiçadas (Figura 3). O pulmão encontrava-se com volume diminuído e havia, também, aproximadamente 1,0L de líquido translúcido.

Ao exame microscópico, o intestino apresentava dilatação e distorção dos vasos linfáticos centrais das vilosidades intestinais (vasos quilíferos), ectasia dos vasos linfáticos da serosa, sendo ocluídos por lipogranulomas, caracterizado por aglomerados de macrófagos, alguns preenchidos por material lipídico amorfo (Figura 4). O pulmão possuía áreas de atelectasia difusa acentuada. Nos linfonodos mesentéricos, presença de macrófagos espumosos 


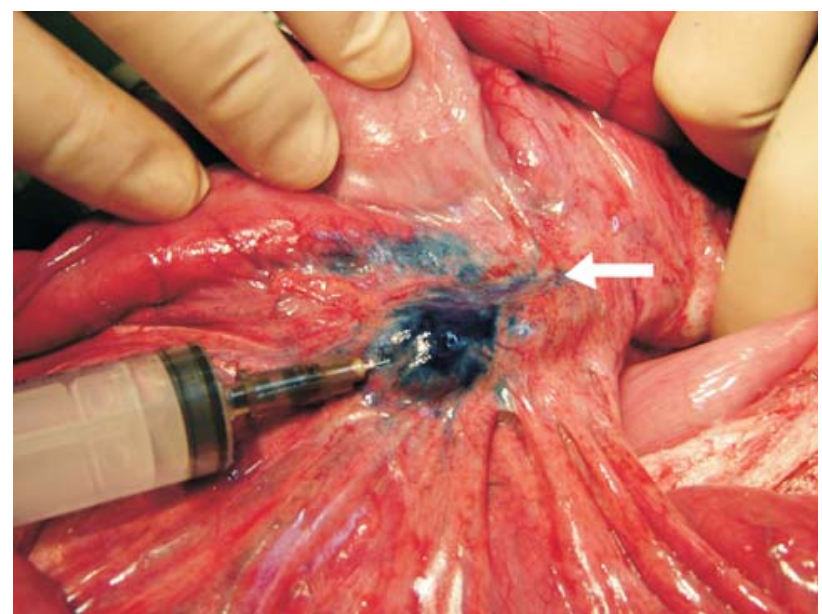

Figura 1. Linfonodo mesentérico. Injeção de azul de metileno, evidenciado a pequena progressão do corante (Seta) em decorrência da obstrução linfática.

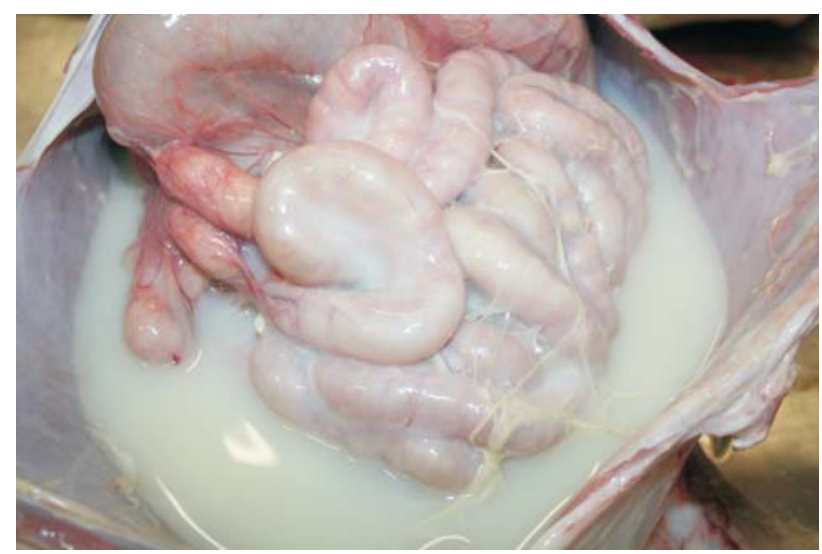

Figura 2. Cavidade abdominal: Presença de grande quantidade (2 litros) de líquido leitoso (ascite quilosa), associado a deposição de fibrina, e alças aderidas observadas durante exame de necropsia.

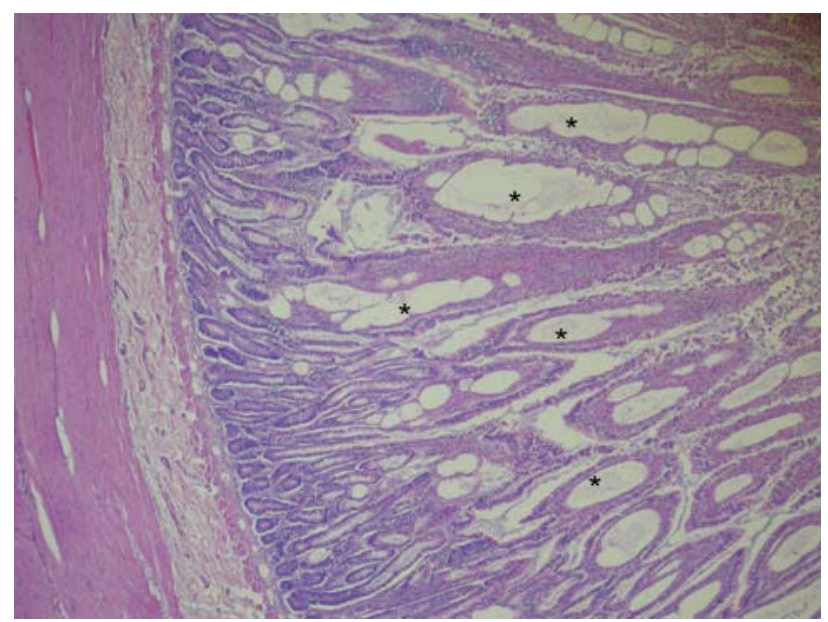

Figura 3. Intestino delgado: Lesões arredondadas, lisas, elevadas, brancas e firmes presentes ao longo da serosa do intestino delgado (destacadas pela elipse). Histologicamente essas lesões correspondiam a lipogranulomas.

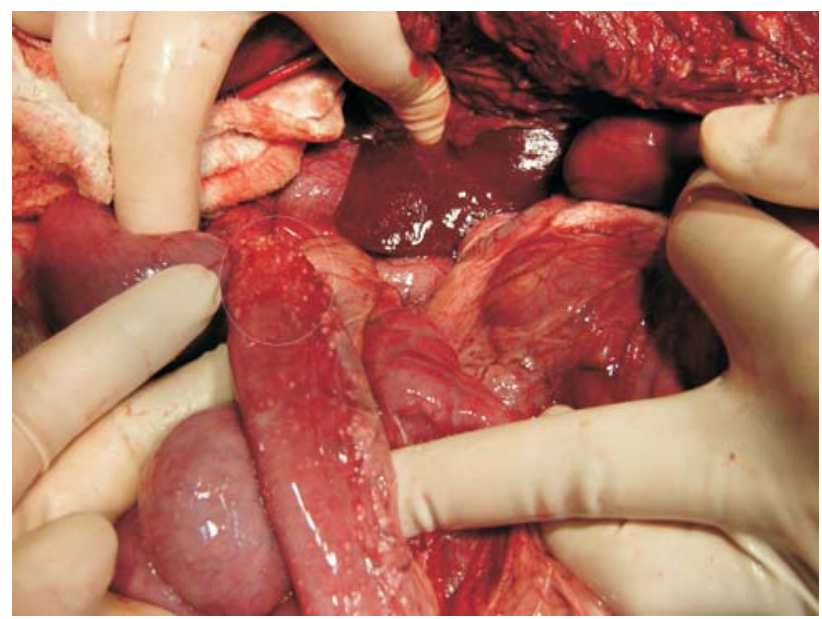

Figura 4. Intestino delgado: Dilatação e distorção acentuada dos vasos linfáticos centrais das vilosidades intestinais (vasos quilíferos). H-E Obj. 20.

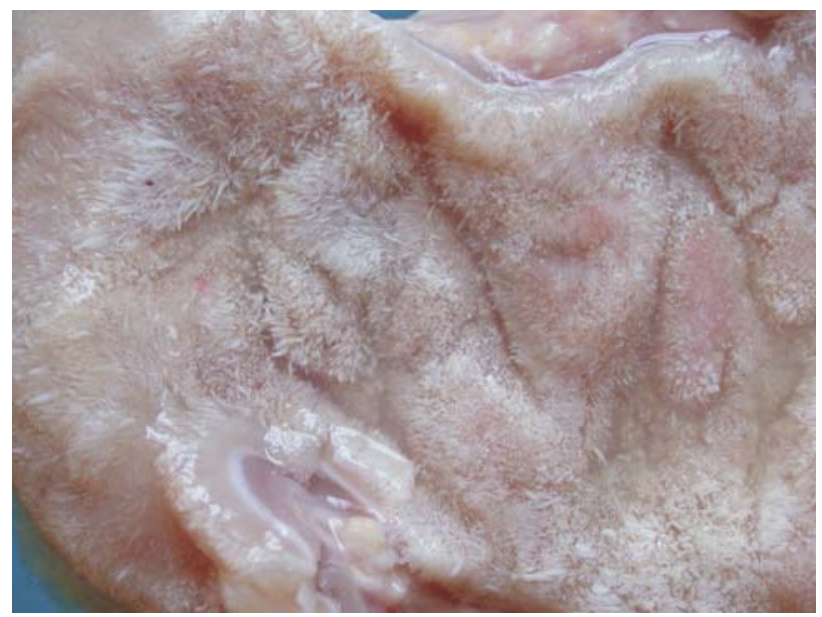

Figura 5. Mucosa do intestino delgado: Apresenta-se pálida, macia e com aspecto aveludado, conferido por vilosidades alongadas e esbranquiçadas.

multifocais moderados com obliteração de vasos linfáticos e presença de trombos hialinos em seu interior. O laudo final da necropsia foi de linfangiectasia intestinal associada à linfangite lipogranulomatosa.

\section{DISCUSSÃO}

Uma apresentação primária e congênita da LI observada em animais jovens, tem sido associada a um número reduzido de linfáticos na mucosa intestinal. Já uma forma secundária e adquirida dessa doença também tem sido descrita, atribuída à hipertensão venosa ou a lesões obstrutivas afetando o sistema linfático $[1,2,6,7,9]$. Apesar de não ter sido possível determinar a causa da LI/LL, por não haver 
diminuição do número de vasos linfáticos durante o exame de necropsia, pode-se sugerir que se trata de uma forma secundária.

A dilatação acentuada da rede linfática intestinal, encontrada durante exame de necropsia, é a responsável pela liberação da linfa no interior do lúmen por meio de ruptura ou extravasamento, causando perda de seus constituintes [1,2,6,11]. A confirmação da presença do quilo nas cavidades torácica e abdominal se deu através da caracterização por análise laboratorial, classificando-o como quilo. Após o tratamento com dieta restrita em calorias pôde-se observar a mudança do líquido para um transudado, provavelmente devido à hipoproteinemia que se agravou na evolução do caso. A hipoproteinemia, como a observada em nosso paciente, se deve a várias causas e é uma das principais alterações encontradas na LI $[2,11,16,17,20]$.

Os exames ecográficos permitiram o acompanhamento da produção de líquidos abdominais e torácicos. As alterações na espessura da mucosa intestinal é atribuída à diarréia crônica que o animal apresentava. As características ultrassonográficas encontradas na LI citadas na literatura referem-se a alterações sugestivas de doença intestinal (aumento da espessura da parede intestinal, hipermotilidade, pequenas corrugações, entre outras), porém, não é possível fazer o diagnóstico diferencial de enteropatias através deste exame [10].

Para a observação dos vasos linfáticos optou-se pela técnica da injeção de azul de metileno no linfonodo mesentérico, que permite uma observação transoperatória do ducto torácico, ao contrário da cateterização linfática, uma técnica mais invasiva ou da linfangiografia que requer radiografia transoperatória [3,4]. A técnica utilizada foi capaz de diagnosticar uma obstrução no fluxo linfático, que foi confirmada durante o exame de necropsia.

A fenestração do diafragma, já descrita na literatura, foi eficiente por pelo menos três semanas, visto que não se observou acúmulo de liquido na cavidade torácica $[15,19]$. A falha deste método deveu-se à cicatrização da região fenestrada, o que pôde ser observada durante o exame de necropsia.

Ocasionalmente a LI é focal, sendo possível a ressecção cirúrgica de pequenas partes do intestino delgado. Tipicamente a afecção é difusa, e a ressecção cirúrgica não é praticável, como foi encontrado durante o procedimento cirúrgico do paciente aqui estudado e confirmado no exame de necropsia [5].
O tratamento da linfangiectasia tem como objetivos a redução da perda entérica de proteína plasmática, resolução da inflamação intestinal ou linfática associada e o controle da efusão ou do edema. A dieta com baixo teor de gordura reduz a absorção da mesma e, por consequiência, diminui a produção de quilo e a dilatação dos vasos linfáticos levando a uma diminuição das efusões. A dieta empregada neste caso foi em parte eficiente, pois reduziu em $80 \%$ a produção de líquido abdominal [2,14,18].

A caquexia do animal deve-se em parte as alterações nas vilosidades intestinais, encontradas durante o exame de necropsia, que levaram a uma má absorção dos nutrientes ingeridos contribuindo com a hipoproteinemia revelada pelos exames laboratoriais.

Os pontos brancos observados, durante o exame de necropsia, na serosa do intestino delgado e distribuídos ao longo da cadeia linfática mesentérica correspondiam histologicamente à LL com a formação de lipogranulomas. Os granulomas lipídicos ocorrem adjacente aos linfáticos ao longo de todo o mesentério do intestino delgado envolvido e se desenvolvem em resposta à substância lipídica encontrada nos linfáticos de alguns cães [5,9,12]. Ainda no exame de necropsia pode-se observar a mucosa do intestino delgado atapetada, e linfáticos mesentéricos esbranquiçados e salientes, alterações essas atribuídas a LI/LL (Figura 5) [6,7].

Neste caso, o diagnóstico foi baseado nos sinais clínicos, evolução da doença e lesões macro e microscópicas. O diagnóstico definitivo de LI/LL foi realizado através do exame histológico do intestino delgado e mesentério associado.

Muitos pacientes conseguem remissão de meses a anos de duração com terapia dietética e antiinflamatória combinada. No entanto, alguns animais falham em responder e muitos, eventualmente, recidivam, para, finalmente, sucumbirem a um esgotamento protéico-calórico severo, derrames incapacitantes ou diarréia intratável $[8,13,14]$. Dessa forma, apesar da resposta à dieta com a diminuição das efusões, a caquexia do animal, a diarréia não controlada e o grau de hipoproteinemia contribuíram para a falha no tratamento clínico que resultou na morte do paciente aqui relatado.

No Brasil, os estudos a respeito dessa condição são escassos. Desconhece-se a prevalência dessa condição nas populações caninas atendidas nos 
Beheregaray W.K., Gianotti G.C., Lamberts M., Pavarini S.P., Ferreira R.R., Lacerda L.A. \& Contesini E.A. Linfangiectasia intestinal associada à linfangite lipogranulomatosa em cão da raça Pit Bull.

diversos estabelecimentos veterinários do nosso país. Assim, se houver maior número de estudos nessa área poder-se-á, no futuro, descobrir a causa e o tratamento para esta patologia, bem como para as alterações que a acompanham.

Agradecimentos: Os autores agradecem à empresa HILL's, ao Laboratório de Análises Clínicas Veterinárias da UFRGS e ao Laboratório da Patologia Animal da UFRGS.

\section{REFERÊNCIAS}

1 Bichard S.J. \& Sherding R.G. 2003. Manual Saunders Clínica de Pequenos Animais. 2.ed. São Paulo: Roca, 1783p.

2 Burrows C.F., Batt R.M. \& Sherding R.G. 1997. Afecções do Intestino delgado. In: Ettinger S.J. \& Feldman E.C. (Eds). Tratado de Medicina Interna Veterinária - Moléstias do Cão e do Gato. São Paulo: Manole, pp.1618-1705.

3 Enwiller T.M., Radlinsky M.G., Mason D.E. \& Roush J.K. 2003. Popliteal and mesenteric lymph node injection with methylene blue for coloration of the thoracic duct in dogs. Veterinary Surgery. 32: 359-364.

4 Fish J.G., Mcneel L. \& Holaday W.J. 1969. Lymphatic obstrution in the pathogenesis of intestinal mucosal atrophy. Annals of Surgery. 169: 316-325.

5 Fossum T.W. \& Rogers K.S. 1998. Linfáticos, Linfonodos, e Tonsilas. In: Slatter D. (Ed). Manual de cirurgia de pequenos animais. 2.ed. São Paulo: Manole, pp.1160-1177.

6 Gelberg H.B. 2007. Alimentary System. In: McGavin M.D. \& Zachary J.F. (Eds). Pathologic Basis of Veterinary Disease. 4th edn. St. Louis: Mosby, pp.357-358.

7 Ilha M.R.S., Loretti A.P. \& Barros C.S.L. 2004. Linfangiectasia intestinal e linfangite lipogranulomatosa em dois caninos. Ciência Rural. 34: 1155-1161.

8 Jeremias J.T., Brunetto M.A., Nogueira S.P., Gomes M.O.S., Munhoz T.D. \& Carciofi,A.C. 2007. Manejo nutricional da linfangiectasia intestinal no cão: relato de caso. Acta Scientiae Veterinariae. 35 (Suppl 2): 550-553.

9 Kruiningen H.J., Lees G.E., Hayden D.W., Meuten D.J. \& Rogers W.A. 1984. Lipogranulomatous lymphangitis in canine intestinal lymphangiectasia. Veterinary Pathology. 21: 377-383.

10 Louvet A. \& Denis B. 2004. Ultrasonographic diagnosis-small bowel lymphangiectasia in a dog. Veterinary Radiology \& Ultrasound. 45: 565-567.

11 Malo D., Gosselin Y. \& Papageorges M. 1982. Entéropathie, avec perte de protéines, secondaire à une lymphangiectasie intestinale, chez trois chiens. Canine Veterinary Journal. 23: 129-131.

12 Meschter C.L., Rakich P.M. \& Tyler D.E. 1987. Intestinal lymphangiectasia with lipogranulomatous lymphangitis in a dog. Journal of the American Veterinary Medical Association. 190: 427-430.

13 Nelson K.L. 2001. Chyloabdomen in a mature cat. Canine Veterinary Journal. 42: 381-383.

14 Seoane M.P.R., De Castro M.P. \& Bittencourt R.C.J. 2007. Linfangiectasia intestinal e quilotórax em um cão. Revista Universidade Rural, Série Ciências da Vida. 27: 269-270.

15 Sicard G.K., Waller K.R. \& Mcnulty J.F. 2005. The effect of cisterna chili ablation combined with thoracic duct ligation on abdominal lymphatic drainage. Veterinary Surgery. 34: 64-70.

16 Tavill A.S. 1971. Protein-losing enteropathy. Journal of Clinical Pathology. 24 [5]: 45-54

17 Vaz M.A.C. \& Fernandes P.P. 2006. Quilotórax. Journal of Brasilian Pneumology. 32: 197-203

18 Waldmann T.A., Morell A.G., Wochner R.D., Warren S. \& Sternlieb I. 1967. Measurement of gastrointestinal protein loss using ceruloplasmin labeled with cooper. Journal of Clinical Investigation. 46: 10-20.

19 Willians J.M. \& Niles J.D. 1999. Use of omentum as a physiologic drain for treatment of chylothorax in a dog. Veterinary Surgery. 28: 61-65.

20 Yuki M., Sugimoto N., Takahashi K., Otsuka H., Nishii N., Suzuki K., Yamagami T. \& Ito H. 2006. A case of proteinlosing enteropathy treated with methotrexate in a dog. Journal of Veterinary Medical Science. 68: 397-399.

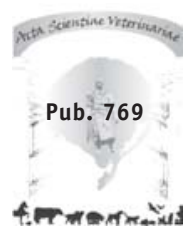

